\title{
Açóes do Governo Federal no combate à coronacrise: limites, insuficiências e escassos acertos
}

\author{
| ${ }^{1}$ Dorival Fagundes Cotrim Junior, ${ }^{2}$ Lucas Manoel da Silva Cabral |
}

Resumo: O artigo analisa as açôes do Governo Federal no contexto do combate à Covid-19, estabelecendo seus limites, insuficiências e mesmo os escassos acertos, conforme dados disponíveis até o momento, haja vista o fato de a Emenda Constitucional (EC) no 106/2020 ter sido recentemente publicada, impossibilitando uma análise real de seus efeitos, razão pela qual se avaliaram seus institutos e possíveis reflexos. Dentre as medidas consideradas estão: Lei no 13.979/2020, Medida Provisória (MP) no 924/2020; Portaria no 395/2020; Plano do Ministério da Economia de R\$ 147,3 bilhōes; MP no 296/2020; Decreto no $10.283 / 2020$; e a EC no $106 / 2020$. Utiliza-se metodologia de abordagem dedutiva e de inferência, no campo teórico, com métodos de procedimento histórico e legal. Por fim, uma série de conclusões são extraídas, são elas: a continuidade do vínculo entre o Governo Federal e a racionalidade neoliberal, que é parte da sua plataforma política, mesmo quando se analisa a EC no 106/2020; a necessidade de revogação da EC no 95/2016, para que se tenha maior margem de atuação na contenção dos danos; e a aferição de que a maior parcela dos recursos injetados pelo Governo Federal neste combate não constituem créditos novos e sim remanejamento e antecipação de valores futuros já previstos, diferindo das posturas estatais internacionais.

> Palavras-chave: Covid-19; neoliberalismo; pacto federativo.

\author{
${ }^{1}$ Instituto de Medicina Social, \\ Universidade do Estado do Rio \\ de Janeiro. Rio de Janeiro-RJ, \\ Brasil (dorivalfcotrim@gmail.com). \\ ORCID: 0000-0002-7389-7635 \\ ${ }^{2}$ Instituto de Medicina Social, \\ Universidade do Estado do Rio de \\ Janeiro. Rio de Janeiro-RJ, Brasil \\ (admlucascabral@gmail.com). \\ ORCID: 0000-0001-6144-8050
}

Recebido em: 29/05/2020 Aprovado em: 09/06/2020 Revisado em: 02/07/2020 


\section{Introdução}

A pandemia causada pelo vírus Sars-CoV-2 traz à tona a importância dos sistemas públicos de saúde, como o Sistema Único de Saúde (SUS), para o enfrentamento da Covid-19 e de seus reflexos socioeconômicos, sobretudo por se basearem nos princípios da equidade, universalidade e integralidade em saúde. Todavia, desde a gestação do SUS, ele é atravessado por diversas forças, contextos e fenômenos que lhe causam dificuldades quanto à implementação, gestão e financiamento, todas consequências das políticas desenhadas, por sua vez afetadas pelos representantes políticos, pelos médios e grandes players do setor privado, e outras expressões dos interesses sociais que estão sempre em disputa.

Essas dificuldades impedem, por exemplo, a implementação dos princípios e

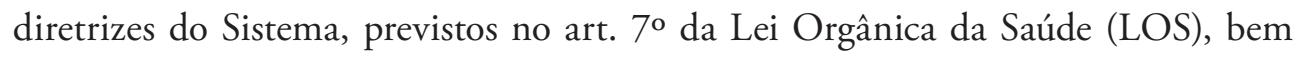
como no art. 198 da Carta Constitucional, respectivamente. Assim, especialmente a partir de 2016, os ataques ao SUS foram potencializados, e de maneira geral contra toda a seguridade social e a educação, a partir da promulgação da Emenda Constitucional (EC) no 95/2016 (VIEIRA; BENEVIDES, 2016; SANTOS; VIEIRA, 2018; VIEIRA, 2018b; VOLPE et al., 2017), assim como das alteraçôes no modelo de financiamento da atenção primária à saúde publicado na Portaria $\mathrm{n}^{\circ}$ 2.979/19, que entrou em vigor a partir de 2020. Inclusive é fundamental revogála o mais rápido possível (ROZNAI; KREUZ, 2018; PINTO; XIMENES, 2018; NORONHA et al., 2018), para que o país consiga ao menos ter a possibilidade minimamente satisfatória no combate à coronacrise, justamente porque a EC, ao implementar o Novo Regime Fiscal (NRF), limita a margem de ação financeira da União, o mais aquinhoado dos entes federativos.

As forças políticas estão se movimentando, dentro de suas próprias limitaçôes, em direção à revogação desta EC do "fim do mundo", como são os casos das nove Açôes Diretas de Inconstitucionalidade (ADIs) impetradas junto ao Supremo Tribunal Federal (STF), assim como a nota pública e o abaixo-assinado contra a EC no 95/2016, intitulado "O SUS não pode morrer", promovido e apoiado pelo Conselho Nacional de Saúde - CNS) (CNS, 2017; CNS, 2020; REDAÇÃO RBA, ${ }^{1}$ 2020; DAVID, 2017).

$\mathrm{Na}$ contramão do mundo, inclusive de países centrais do sistema interestatal capitalista (FIORI, 2014), o Governo Bolsonaro vem se utilizando da pandemia 
da Covid-19 para perseguir e perseverar em sua racionalidade embasada no neoliberalismo, que lhe é marca característica (SANTOS, 2020; OLIVEIRA; VERONESE, 2019; ALMEIDA, 2019), bem como para continuar a mobilização incessante da sua base eleitoral, de ainda assombrosos um terço dos eleitores nacionais (SHALDERS, 2019), ${ }^{2}$ o que possivelmente e a seu turno revela que essa parcela do contingente populacional o deseja, talvez por lhe ser igual em aspirações, desejos e norma de comportamento e de vida (LAGO, 2020).

Assombroso, criminoso e asqueroso o negacionismo do Presidente da República em face da pandemia do novo coronavírus, decretada pela Organização Mundial da Saúde (OMS) em 11 de março de 2020, e que até o dia 16 de maio já tinha infectado mais de 4,6 milhôes de pessoas em todo o planeta, sendo 233.511 só no Brasil, que contabiliza 15.662 óbitos (JOHNS HOPKINS, 2020). ${ }^{3}$

Santos (2020) associa o modus operandi do governo ao conceito de "capitalismo do desastre" (KLEIN, 2008), que, em linhas gerais, atua associando choques coletivos e movimentos de ruptura nos regimes de bem-estar social, aproveitando-se do momento de fragilidade para impor, autoritariamente, açôes que coadunam com a racionalidade neoliberal. Em continuação, as forças do capital se aproveitam inescrupulosamente "dos períodos de crises econômicas, guerras, desastres naturais, ataques terroristas e epidemias, para assaltar os interesses públicos nacionais e locais e levar a cabo todo tipo de reformas a favor do livre mercado" (MARIANO, 2017, p. 279).

No Brasil se pode dizer que, desde a crise econômica de 2008 e o golpe jurídico-parlamentar que afastou a presidente Dilma Rousseff (MARIANO, 2017; ALMAGRO-CASTRO, 2019; BASTOS, 2017; DOMINGUES, 2017), o país vive sob a doutrina do choque/do capitalismo de desastre, perpetuado até então e potencializado pela pandemia. Em face de tantas questóes, tornam-se cabais açôes políticas reforçadas, orientadas, unidas e atentas dos movimentos sociais, organizaçóes acadêmicas, instituiçôes democráticas, partidos de oposição e da população em geral contra as possíveis tentativas do governo de aproveitar-se da pandemia, obstaculizando a transformação do estado de calamidade pública para um estado de exceção, no qual não há garantias mínimas de sobrevivência de um já parco Estado de bem-estar social, também marcado pela tentativa de concentração de poderes em suas mãos e da manutenção do capitalismo do desastre, que está sempre à procura de dificuldades sensíveis para impor ainda mais as medidas de austeridade fiscal. 
Agora se torna possível adentrar nas ações do Governo Federal para o enfrentamento da coronacrise, com ênfase em dois ministérios, da Saúde (MS) e da Economia (ME).

\section{A Lei no $13.979 / 2020$ e a MP no 924/2020}

A Lei no $13.979 / 2020$ foi a primeira medida legal nacional para o enfrentamento da emergência em saúde pública decorrente do Sars-CoV-2, que trouxe uma série de questionamentos, e sendo publicada em 6 de fevereiro de 2020, dias após a OMS ter declarado a Emergência de Saúde Pública de Importância Internacional (ESPII).

Destaque importante desta lei é o parágrafo terceiro do art. $1^{\circ}$, determinando que a duração da situação de emergência de saúde pública nacional determinada pelo ministro da Saúde não poderá ser superior ao prazo declarado pela OMS. Tal norma representa uma interessante medida de contençáo de poder entre os poderes, ao nosso olhar acertada, e que serve para frear eventuais tentativas de postergar este quadro emergencial por motivos escusos, misteriosos ou ilícitos, sobretudo quando se consideram as alteraçóes jurídicas que ocorrem quando se decreta esse tipo de emergência. Todo cuidado é bem-vindo.

Um segundo destaque diz respeito à previsão de "autorização excepcional e temporária para a importaçáo de produtos sujeitos à vigilância sem registro na Anvisa" (art. 30), desde que sejam atendidas cumulativamente duas condiçóes: (i) estar registrado por alguma autoridade sanitária estrangeira e (ii) estar previsto em ato regulador do ministro da Saúde, ou mesmo de gestores locais de saúde (vide parágrafo sétimo do mesmo artigo), desde que autorizados pelo MS.

Uma das possíveis complicaçóes aqui é o aparente caráter de irrestritabilidade da norma, ao apenas mencionar que basta o produto estar registrado por alguma autoridade sanitária estrangeira. Ou seja, qualquer autoridade de qualquer país, caso venha autorizar o registro de certo produto, possibilita que este figure como possibilidade de combate ao vírus no entendimento do governo brasileiro e logo, como cotável à importação, sem considerações de ordem científica que garantem um mínimo seguro de eficácia e de redução de danos. Quando se lembra dos ataques que a ciência vem sofrendo pelo Governo Federal, isso deixa de ser uma surpresa, em que pese continuar figurando como um grande perigo, infelizmente.

Estritamente vinculada a esta lei tramitou em regime de urgência a Medida Provisória (MP) no 924, sancionada em 13 de março do presente ano, que supostamente 
abriria crédito extraordinário de $\mathrm{R} \$ 5$ bilhôes em favor dos ministérios da Saúde e da Educação a ser aplicado no combate à Covid-19. Acontece que não tratou de crédito extraordinário, mas de remanejamento de verbas de dois fundos públicos, o Fundo Nacional para o Desenvolvimento da Educação Básica (FUNDEB) e o Fundo Nacional de Saúde (FNS) (SANTOS, 2020). Ou seja, tal crédito supostamente extraordinário foi apenas uma antecipação de recursos já previstos no orçamento federal como gastos e não como "crédito novo", como verdadeiramente adicional. Em tempos de fake news, é precioso checar todas as informaçôes e pesquisar em fontes seguras, para além dos mensageiros instantâneos virtuais.

\section{Portaria no 395/2020 e o Plano do Ministério da Economia}

A Portaria no 395/2020, publicada três dias após a MP no 924/2020, previu a liberação da quantia de $\mathrm{R} \$ 424$ milhóes, a ser liberado em parcela única, a ser empregada nas açóes de combate ao Sars-CoV-2 pelos entes estaduais e o Distrito Federal, cabendo-lhes definir o modo de aplicação dos valores, desde que voltados para as ações de média e alta complexidade, o que inclui, como se sabe, serviços ambulatoriais e hospitalares do SUS.

$\mathrm{O}$ art. $1^{\mathrm{o}} \mathrm{da}$ portaria oferece prova cabal da baixa quantia que isso representa quando se considera o contingente populacional do país, uma vez que corresponde a apenas $\mathrm{R}$ \$2,00 per capita, tomando como base as projeçóes demográficas do Instituto Brasileiro de Geografia e Estatística (IBGE) para 2020. Menciona-se ainda o pacote apresentado pelo ministro da Economia, Paulo Guedes, após cinco longos dias da declaração da pandemia feita pela OMS para minimizar os efeitos da coronacrise, prometendo injetar a quantia de $\mathrm{R} \$ 147,3$ bilhóes na economia, consoante três grandes eixos definidores: (i) atençâo às populaçôes mais vulneráveis; (ii) manutenção empregatícia; e (iii) combate à pandemia em si (MELLO et al., 2020). O primeiro eixo engloba medidas que geram impactos da ordem de $\mathrm{R} \$ 83,4$ bilhôes na economia; o segundo da ordem de R \$ 59,4 bilhôes; e o terceiro de R \$ 4,5 bilhôes (MELLO et al., 2020).

A situação, entretanto, é diversa daquela anunciada pelo atual Governo Federal, tâo acostumado a mentiras e falseamentos, pois aqui também não se trata de recursos novos (mais créditos). As açóes no front econômico constituem, em sua maioria, remanejamento orçamentário, diverso do que ocorre em outros países, 
como nos próprios Estados Unidos, em que uma das propostas foi o cheque de mil dólares a ser entregue aos cidadãos.

No Brasil, a seu turno, o auxílio emergencial ${ }^{4}$ à população no valor de $\mathrm{R} \$ 600,00$ foi trabalho do Congresso Nacional, e não do Governo Federal, pois este inicialmente não se prontificou a agir neste sentido. Em seguida, após as diversas pressões, anunciou que estudaria um auxílio de $\mathrm{R} \$ 200,00$. Felizmente, o Congresso se antecipou e estabeleceu este auxílio, minimizando certamente os reflexos socioeconômicos da Covid-19, mas como o Executivo ainda controla os repasses problemas continuam a surgir, como a imensa quantidade de pessoas ainda em análise, e ao atraso no pagamento da segunda parcela para quem já recebeu a primeira, que já contabiliza mais de 15 dias. Inadmissível tal situação em um país de know-how já consolidado quanto ao pagamento de auxílios nacionais, como se verifica com o Programa Bolsa Família. Portanto, parece não se tratar de dificuldades operacionais, mas de incompetência na gestão e falta de vontade política.

Ainda na linha do plano de auxílio do Ministério da Economia, insuficiente e que pouco inova em relação a créditos novos, o governo decretou renúncia fiscal agregada de $\mathrm{R}$ \$ 52,2 bilhóes, beneficiando empresas com a dispensa de recolhimento do FGTS e do Simples Nacional, assim como adiando o prazo de pagamento de tributos, o que configura medida acertada, sobretudo para os pequenos e médios empreendimentos, que já sentem o forte impacto da crise.

\section{Perpetuidade da disciplina (in)sustentável do NRF e o gargalo dos testes}

A questão de ordem mais geral, e que conversa com a EC no 95/2016 é o fato de as açóes do governo continuarem respeitando à risca a (i) disciplina fiscal imposta pela emenda do "teto de gastos", as (ii) exigências de superávit fiscal e (iii) a "regra de ouro" (art. 167, III da CF 88), que impede investimentos públicos, nos termos do NRF (SANTOS, 2020). Do ponto de vista prático, isso significa que em eventual disputa entre a necessidade de se gastar mais recursos para salvar vidas e o respeito ao NRF, imposto pela EC no 95/2016 e suas muitas convicçóes, prefere-se este último, ainda que venha resultar em mortes e outras flagelaçóes de caráter permanente. Assim, as circunstâncias especiais do momento indicam a necessidade de revogação imediata da emenda, a fim de que o Estado consiga lidar mais satisfatoriamente com a pandemia, preservando as vidas dos seus habitantes, o bem jurídico mais basilar de todos e sem o qual não há possibilidade de formação social. 
Imperioso exemplificar as consequências desta disciplina fiscal de austericídio ${ }^{5}$ e da desindustrialização crescente, como se percebe na falta dos equipamentos de proteção individual (EPIs) nos hospitais e postos de saúde, utilizados pelos profissionais de saúde. No estado de São Paulo, por exemplo, esses profissionais estão se organizando para comprar equipamentos (EPIs) por conta própria, garantindo um mínimo de proteção digna e de respeito à própria vida. Contudo, estudos apontam riscos reais de desabastecimento desses equipamentos, uma vez que o MS não dispóe de estoques nacionais e as compras internacionais foram canceladas, ${ }^{6} \mathrm{com}$ imenso pesar.

Outro dos gargalos do combate nacional (mas também internacional em um primeiro momento) à pandemia encontra-se na falta de testes para a Covid-19, tanto pela inexistência de materiais quanto pela falta de verba, apesar da recomendação da OMS para realização de testagem em massa. Em 24 de março, o governo anunciou a compra de $\mathrm{R}$ \$ 4,3 milhōes de testes moleculares da Fundação Oswaldo Cruz (FIOCRUZ) e de empresas privadas, além de mais 600 mil doados pela Petrobras, mas que ainda são insuficientes para cobrir parcela considerável da população do país. Um mês depois, o MS ampliou a previsão inicial de testes, que era de 23,9 milhôes de testes para 46,2 milhóes, tanto por compra direta quanto por doação. Deste total, 24,2 milhôes de testes são RT-PCR (biologia molecular) e 22 milhôes de testes rápidos (sorologia) (BRASIL, 2020d).

No âmbito internacional, um dos maiores entraves para a produção é a altíssima demanda generalizada das substâncias químicas que possibilitam a identificação do Sars-CoV-2, poisapenas 12 Estados-membros da ONU não tiveram casos confirmados até 15 de maio deste ano. A alta procura causou igualmente o encarecimento dos preços dos insumos existentes, sendo que o Brasil tem uma terceira peculiaridade que afeta a aquisição destes materiais para fabricação, a desvalorização do real e a consequente alta do dólar e do euro (BARIFOUSE, 2020).

Um quarto fator levantado pela literatura especializada é a baixa capacidade nacional de processamento e análise das amostras, pois apenas a FIOCRUZ, o Instituto Adolf Lutz, o Instituto Evandro Chagas e os 27 Laboratórios Centrais de Saúde Pública (LACENs) estão aptos a tal ação.

Inviável e equivocado pensar que a saída para uma testagem em massa ocorresse apenas pelos testes rápidos, no qual uma ou duas gotas de sangue são postas em contato com reagentes químicos para mostrar se há anticorpos contra o vírus, uma vez que o teste sorológico apenas vai dizer se a pessoa já teve contato com o vírus a 
partir da produção de anticorpos; só com 14 dias após infectado é que sua eficiência vai chegar a $80 \%$, alcançando $85 \%$ a $90 \%$ com 21 dias; e ainda há risco de reação cruzada (quando outro agente infeccioso estimula a produção de anticorpos).

Todo o contexto, repleto de dificuldades, demonstra que será preciso abrir as "chaves do tesouro" nacional para que se combata efetivamente a coronacrise e seus reflexos da forma menos prejudicial possível à população.

\section{Desbloqueio e dissolução parcial do ativo garantidor}

Outra medida anunciada pelo governo é antiga demanda do setor da saúde complementar no país (setor privado), a dissolução do Fundo Garantidor (ou ativo garantidor) que serve de proteçáo ao consumidor dos planos privados. A medida foi de dissolução parcial, mas representa mais uma "imediata fragilização do Estado" no controle do mercado de saúde. Assim, em obediência às "convicçôes fiscais" do Ministério da Economia houve o desbloqueio de R \$ 10 bilhóes deste Fundo, mantido pelas operadoras de saúde junto à Agência Nacional de Saúde Suplementar (ANS) para que invistam em equipamentos e expansão de leitos privados (SANTOS, 2020).

$\mathrm{O}$ ativo garantidor é a porcentagem bloqueada pela ANS para proteger os clientes das empresas prestadoras caso venha a ocorrer algum problema de ordem econômico-financeira com elas, e expressa o cuidado que o Estado precisa ter com seus administrados. Para se ter uma dimensão do tamanho do Fundo, até julho de 2019 o valor retido pela ANS era de R\$ 50,9 bilhóes (OUTRA SAÚDE, 2019). ${ }^{7}$

\section{MP no 296/2020 e a dispensa dos procedimentos licitatórios}

A MP no 296/2020 trouxe outra grande ação de impacto, alterando também a Lei no 13.979/2020 quanto aos "procedimentos para aquisiçáo de bens, serviços e insumos destinados ao enfrentamento da emergência de saúde pública de importância internacional decorrente do coronavírus" (BRASIL, 2020c), passando a dispensar, os termos do art. $1^{\circ}$ do referido diploma os processos públicos de licitação para a compra e aquisiçốes de mercadorias ligadas à área da saúde. Pragmaticamente, isso significa a liberalização e o "favorecimento concreto da corrupção venal" (SANTOS, 2020, p. 6) tornando-se dispensáveis certos institutos basilares para a manutenção da saúde financeira e da ética da Administração Pública, como o menor preço, o caráter idôneo das empresas e a observância destas quanto aos seus deveres fiscais e trabalhistas. 
Não se trata de desprezar o caráter emergencial e mesmo crítico da situação deflagrado pelo novo coronavírus, o que justificaria a necessidade de agilizar os procedimentos aquisitivos dos entes federativos. Lança-se a reflexão para demonstrar a abertura inegável de um flanco para os aproveitadores e corruptos, que desconhecem ou fingem não conhecer os princípios do Direito Administrativo, como os da impessoalidade e da moralidade do direito público.

\section{Decreto no 10.283/2020 e a criação da Agência para o Desenvolvimento da Atenção Primária}

A sexta medida analisada foi a criação da Agência para o Desenvolvimento da Atenção Primária (ADAPS), que aprofunda e beneficia indubitavelmente o setor privado em saúde, em detrimento dos objetivos de "controle público da saúde", a partir do SUS (SOUZA et al., 2019). ${ }^{8}$

O serviço social autônomo (SSA) denominado ADAPS foi criada pelo Decreto no 10.283, de 20 de março de 2020, na forma de pessoa jurídica de direito privado sem fins lucrativos, de interesse coletivo e de utilidade pública, tendo como finalidade "promover, em âmbito nacional, a execução de políticas de desenvolvimento da atenção primária à saúde em caráter complementar e colaborativo com a atuação dos entes federativos".

À primeira vista até parece uma boa política, mas significa na prática, conforme anunciam várias entidades e coletivos da saúde coletiva do país, a abertura de mais uma via de "contratação de serviços privados para prestação assistencial de saúde à população" (SANTOS, 2020, p. 5) Ou seja, trata-se de privatização, com o consequente sucateamento dos serviços, pagamentos, administração e gestão em si da atenção primária, como ocorreu e ocorre com as Organizaçôes Sociais (OSs) espalhadas por todo o país (MORAIS, 2018). Giovanella et al. (2019) igualmente asseveram e rememoram que a disputa pelos recursos públicos por empresas do setor privado, agora sob a forma de corporaçôes financeiras que gerenciam hospitais e planos de saúde, sempre marcantes na história da saúde brasileira, torna-se ainda mais agressiva em situaçôes de desregulamentação, como no contexto atual.

A criação de um SSA com prerrogativas de contratação de empresas privadas para que estas prestem a atenção transforma a APS em lócus mercantil, aproximando-a e todo o sistema público das propostas de cobertura universal de saúde. Outro 
elemento favorecedor do setor privado é o assento de entidades privadas no colegiado gestor da ADAPS, significando a inclusão de atores privados na tomada de decisão política voltada à APS. "Abre-se caminho para a privatização da APS, que tem sido considerada a parte mais estatal da rede de serviços do SUS, com uma enorme vocação não mercantil" (GIOVANELLA et al., 2019, p. 4).

Ocké-Reis (2020, p. 9), ao ser questionado sobre o sentido da proposta da ADAPS, asseverou categoricamente que é o de "criar uma organização que contrate médicos, por meio da CLT, para atuar nos espaços vazios assistenciais"; e pelo conjunto de atribuiçôes da agência os entes municipais podem perder funçôes, especificamente os gestores locais, já que a agência contratará diretamente as equipes gestoras. $\mathrm{Ou}$ seja, com o decreto o Governo Federal passa a estimular as relaçóes contratuais com o setor privado, reforçando a tendência de privatização da gestão e também da operacionalização da atenção, eis que a ADAPS tem como perspectiva contratação pessoal por meio de OSs e cooperativas de pessoas jurídicas.

Esse novo arranjo para a contratação de pessoal foi facilitado pela alteração na forma de financiamento federal da atenção primária à saúde, ocorrida em 2019 (MELO et al., 2018; MENDES; CARNUT; GUERRA, 2018). Ela definiu que a transferência de recursos do Governo Federal para as equipes de Saúde da Família seja calculada somente a partir da população cadastrada nas clínicas da família, e não mais considerando o conjunto da população residente nos municípios, o que certamente acarretará perdas de grande monta (SANTOS, 2020).

\section{A Emenda Constitucional no 106/2020 (antiga PEC do Orçamento de Guerra)}

A outrora PEC no 10/2020, mais conhecida como Proposta do Orçamento de Guerra, após uma tramitação de 31 dias, que pode ser considerada muito rápida, nas duas casas legislativas, acabou aprovada, promulgada e publicada em 8 de maio de 2020, instituindo uma espécie de regime fiscal, financeiro e de contrataçôes extraordinário, sendo mais uma das medidas do país para o enfrentamento da coronacrise.

Dada sua relevância no combate à pandemia e alguns aspectos intrigantes que serão pontuados faz com que ela esteja aqui no rol das açôes, sem a qual a análise de âmbito conjuntural estaria precarizada, já que toca em um dos pontos centrais que vêm sendo levantado: o contingenciamento imposto ao Estado, desde a Lei de 
Responsabilidade Fiscal até, pelo menos, a EC no 95/2016. Basta dizer, por exemplo, que ela afasta a incidência da regra de ouro (art. 167, III da CF 88) nas açóes voltadas ao combate da pandemia.

Desde logo é importante situar o caráter temporário da emenda quanto à sua vigência, conforme exposto em seu art. 11, que consigna expressamente a revogação automática da medida "na data do encerramento do estado de calamidade pública reconhecido pelo Congresso Nacional", previsto até 31 de dezembro de 2020. O "regime extraordinário fiscal, financeiro e de contrataçôes", nos termos do art. $1^{\circ}$ da EC, apenas se aplicará às açóes cujo objetivo seja o de atender as necessidades decorrentes da pandemia, mas não todas e sim apenas aquelas em que não sejam possíveis de serem satisfeitas com o regime regular. Ou seja, será válido para os casos em que seja verificado o requisito da urgência. Não se trata de uma EC muita extensa em número de artigos, mas seus efeitos têm potencial de serem bem consideráveis, expressando mais uma razão para considerá-la no levantamento das ações de enfrentamento à crise.

Mas em que consiste esse regime extraordinário, ou, em outros termos, em quais normas ele se desdobra? Analisemos, ainda que brevemente, os pontos mais cruciais para um planejamento e gestão em saúde no curso da pandemia.

$\mathrm{O}$ art. $2^{\circ}$ da EC trata dos processos simplificados de contratação no âmbito do Poder Executivo federal e suas competências, que poderão (e não deverão) ser adotados para (i) contratação de pessoal, em caráter emergencial e temporário; e (ii) contratação de obras, serviços e compras. Pela dimensão da crise o Congresso entendeu por adotar estas medidas simplificadoras para dar agilidade na resposta do Estado à pandemia, mesmo que represente uma exceçấo constitucional à obrigatoriedade da observância das regras do concurso público e da licitação.

Obviamente, esses processos simplificados apenas serão válidos se tiverem como finalidade exclusiva de enfrentamento da calamidade pública e seus respectivos reflexos socioeconômicos, no curso da sua temporalidade e náo ad eternum. A contratação temporária, prevista no art. 37, IX da CF 88 poderá prescindir da exigência do parágrafo primeiro do art. 169 do mesmo diploma jurídico, que, em linhas gerais, prevê a necessidade de prévia dotação orçamentária e de autorização específica na Lei de Diretrizes Orçamentárias (LDO). Portanto, a contratação por tempo determinado está dispensada desta exigência, desde que voltada para conter a calamidade pública, e, o que também é crucial, continuará sendo objeto de tutela 
e investigação dos órgãos de controle, o que é de especial relevância, especialmente quando se conhece os potenciais problemas decorrentes de contrataçôes simplificadas, como o favorecimento de certos atores em detrimento de outros.

O parágrafo único desse artigo ainda prevê a necessidade de adoção de "critérios objetivos, devidamente publicados" para "distribuição de equipamentos e insumos de saúde” pela União aos estados e municípios, desde que voltados ao enfrentamento da Covid-19. Todavia, o Congresso Nacional pode ter falhado ao deixar esta regulamentação para o Governo Federal, uma vez que, como se tem presenciado, este não tem adotado uma postura de seriedade e compromisso no enfrentamento à pandemia e seus efeitos, mesmo quando o número de mortos já tenha ultrapassado a cifra de 16 mil em todo o país. Talvez já pudesse ter delineado pelo menos algumas açóes de ordem mais geral a respeito da distribuição dos equipamentos e insumos de saúde, cruciais para minimizar os danos, pelo menos. Outra das medidas previstas é a dispensa das limitaçóes legais ao aumento de despesa e renúncia de receitas, desde que tais atos não impliquem despesas permanentes, consoante o exposto no art. $3^{\circ}$ da EC, cuja redação anfibológica pode vir a causar certos prejuízos.

Já há elementos suficientes para perceber a importância de se discutir esta medida, especialmente quando ela estabelece uma série de exceçóes a regras que são consideradas como de primeira ordem no ordenamento e na racionalidade neoliberal dominante que sustenta as convicções de arrocho fiscal e de limitaçóes de gastos a qualquer custo. E outra das alteraçôes na normativa constitucional feitas pela EC no 106/2020 está na possibilidade, então vedada, das empresas com débitos previdenciários contratarem com a Administração Pública ou mesmo receberem benefícios e incentivos de ordem fiscal ou creditício, afastando o conteúdo do parágrafo terceiro do art. 196 da CF 88.

Três questionamentos, no mínimo, podem ser feitos quanto a essa alteração: será que o país não dispóe de um mercado numeroso o suficiente para manter essa restrição sem que afete o combate a pandemia e aos seus reflexos? No conjunto dessas empresas devedoras, haveria uma ou algumas tão imprescindíveis assim no oferecimento de produtos/serviços úteis a esse combate? E será que o estado de calamidade pública justifica o afastamento de regra tâo importante do ordenamento, baseada nos princípios da moralidade, da impessoalidade e no vetor axiológico da dignidade humana? Em nome da pandemia todas as regras poderão ser flexibilizadas? 
Uma questão é afastar, temporariamente, a obrigatoriedade do concurso público; e outra bem diversa é permitir que empresas devedoras da Previdência, que prejudica tanto os trabalhadores no nível individual quanto à coletividade, pois afetam negativamente a sustentabilidade da própria previdência pública, contratem novamente com o Poder Público. Quem garante que elas não continuarão a agir da mesma forma? Esse não é um questionamento de menor importância, ou mesmo de implicância, mas que ajuda na reflexão a respeito de qual país queremos manter e construir, de quais regras são fundamentais e que não devem ser afastadas.

Outra das medidas importantes, e que coaduna com diversas entidades da saúde coletiva, diz respeito ao afastamento da "regra de ouro" do art. 167, III da Carta Cidadã no enfrentamento à pandemia. A regra de ouro, em linhas gerais, veda a realização, pelo governo, de operaçóes de crédito9 (que geram endividamento) em valores superiores às despesas de capital, ${ }^{10}$ excetuadas aquelas autorizadas pelo Legislativo por maioria absoluta. Ou seja, impede o governo de contrair dívidas que excedam o valor de suas despesas de capital - gastar mais do que arrecada e ganha (PISCITELLI, 2018). Assim, em todo o exercício financeiro da calamidade (ano de 2020), a Administração Pública estará dispensada de cumprir a regra de ouro, que lhe possibilitará gastar a mais com despesas de custeio, como as de caráter pessoal, que se materializa na contratação de médicos, enfermeiros e profissionais de saúde; bem como na compra de materiais consumíveis como remédios, EPIs, alimentos, considerando que são extremamente necessários no combate à pandemia e seus efeitos, sobretudo para a preservação das vidas. ${ }^{11}$

$\mathrm{O}$ art. $5^{\circ}$ da EC prevê, a seu turno, que seja estabelecida uma programação orçamentária específica para esses gastos (relacionadas à calamidade), contando com marcadores que as identifiquem; assim como uma prestação de contas a ser avaliada e evidenciada separadamente.

$\mathrm{O}$ artigo seguinte determina que os recursos provenientes das operaçóes de crédito realizadas para o refinanciamento da dívida mobiliária (constituída pelos títulos públicos emitidos pelo Tesouro Nacional) poderão ser utilizados para o pagamento de seus juros e encargos, garantindo assim que os investidores em renda fixa ou em outros títulos que aplicam nos papéis públicos sejam pagos, tenham liquidez e continuem a investir no Estado. Representaria isso um desvio da estrutura dorsal na emenda, já que não está diretamente relacionada no combate à pandemia? 
Um dos maiores objetos de crítica e debate da emenda, desde quando tramitava na forma de PEC, também foi aprovado: a autorização dada ao Banco Central para comprar e vender títulos de emissão do Tesouro e outros ativos. As operaçóes de compra e venda dos títulos do Tesouro poderão ocorrer nos mercados secundário local e internacional, sendo que os que estáo em mercados secundários nacionais devem ter (i) classificação (de risco de crédito) equivalente a BB- ou superior, auscultada por pelo menos uma das três maiores agências internacionais de classificação de risco; e (ii) preço de referência publicado por entidade do mercado financeiro acreditada pelo Banco Central brasileiro, sendo dada preferência à aquisição de títulos emitidos por microempresas e por empresas de pequeno e médio porte.

A alienação de ativos adquiridos desse modo poderá ocorrer em data posterior à vigência do estado de calamidade, caso o interesse público assim justifique, o que é no mínimo problemático do ponto de vista da segurança jurídica, trazendo em si ainda um dispositivo vago (de baixa densidade normativa) e que comporta múltiplas açôes.

Importante dispositivo de controle está contido no art. 9o, que reza a possibilidade de o Congresso Nacional sustar, por decreto legislativo, as decisóes do Executivo que descumprirem a emenda, funcionando, para além das corregedorias e tribunais de conta, como mais uma instância de avaliação e observação dos atos do Executivo, atualmente em situação bem delicada. Tal medida é também sintoma do protagonismo que o Congresso vem tendo no contexto da coronacrise, fazendo com que o país se aproxime, cada vez mais, de um parlamentarismo, embora o presidente ainda detenha parcelas significativas de exercício de poder.

Por fim, o artigo décimo, e último, consigna a convalidação dos atos adrede praticados pelo Executivo, a partir de 20 de março de 2020, desde que compatíveis com a substância da emenda.

\section{O cumprimento do receituário neoliberal}

Agora já parece possível afirmar que o Governo Federal não se tem afastado da "agenda neoliberal que o elegeu" (SANTOS, 2020, p. 8) mesmo com o "regime extraordinário fiscal, financeiro e de contrataçôes" instituído pela EC no $106 / 2020$, pois ainda que flexibilize a regra de ouro, isto ocorre temporariamente; além de possibilitar a compra e venda de títulos nos mercados secundário local e internacional; e prevê a utilização dos recursos advindos de operaçôes de crédito para o pagamento dos juros e encargos da dívida. Isso também não substitui a disputa 
pela revogação da EC no 95/2016 e de uma reavaliação da Lei de Responsabilidade Fiscal, como diversas entidades da saúde e outras forças coletivas do campo mais progressista estáo pautando.

Ainda é cedo para dizer se o novo regime fiscal temporário estabelecido para o combate à pandemia influenciará positivamente e em que medida isso se dará, mas a catástrofe no país é iminente, como os números da Covid-19 já indicam, e deste caos se aproveita o presidente para sustentar e atiçar os seus apoiadores, promovendo e participando de agitaçooes políticas, talvez como uma forma de sobrevida (SANTOS, 2020), diante das sucessivas baixas que sua coalizão mais ampla vem sofrendo. Portanto, como posto no início, parece ser possível afirmar que o estado de calamidade pública vem sendo mostrado e aproveitado estrategicamente como um "excludente de ilicitude, um salvo conduto, para que o governo aprofunde a tática de terra arrasada contra o marco social da Constituição de 1988" (MARIANO, 2017, p. 265) tal como prevê a racionalidade neoliberal e cujo exemplo histórico foi o Chile. Além disso, é possível verificar em mais de uma dessas medidas ventiladas um favorecimento ou ao menos uma facilitação à corrupçáo no seio estatal, com possibilidade de empresas devedoras da Previdência contratarem novamente com a Administração Pública.

Considerando este modo de operação a pandemia de Covid-19 está sendo manobrada como possibilidade de materialização da "doutrina do choque" (KLEIN, 2008, p. 328) tratando-se de um capitalismo de "desastre", que, ao se alimentar das diversas e profundas crises, reforça e radicaliza o receituário neoliberal de alteraçóes sistêmicas. Assim o Governo Federal continua apresentando respostas ao seu eleitorado mais fiel, o núcleo duro da ideologia bolsonarista de extrema-direita.

\section{Considerações finais}

É certo que nem todas as medidas foram comentadas, mas há aqui um roteiro significativo das açóes do Governo Federal em face da Covid-19, dentre as quais: (i) a Lei no 13.979/2020, (ii) a MP no 924/2020; (iii) a Portaria $n^{\circ} 395 / 2020$; (iv) o Plano do Ministério da Economia de R \$ 147,3 bilhóes; (v) a MP no 296/2020; (vi)

o Decreto no 10.283/2020; e (vii) a EC no 106/2020.

Dentre as conclusôes estáo:

(i) a continuidade do vínculo entre o Governo Federal e a racionalidade neoliberal, que é parte da sua plataforma política, mesmo quando se analisa a EC no 106/2020 (do orçamento de guerra); 
(ii) a necessidade de revogação da $\mathrm{EC}$ no 95/2016 para que se tenha maior margem de atuaçáo no combate ao Sars- $\mathrm{CoV}-2$ e à Coronacrise;

(iii) a aferição de que a maior parcelc dos recursos injetados pelo Governo Federal nesse combate não constitui créditos novos (mais dinheiro), e sim remanejamento e antecipação de valores futuros já previstos, diferindo das posturas estatais internacionais;

(iv) a associação existente no país, desde o Golpe de 2016 até agora na ação contra a Covid-19, entre o modo de operação do Governo Federal e a tese do "capitalismo de desastre", que, em síntese, é a postura de aproveitamento de crises e momentos de fragilidade para impor medidas do receituário neoliberal;

(v) a necessidade de atuação política atenta dos sujeitos coletivos e individuais para impedir a possível passagem do estado de calamidade pública para um estado de exceção, com a concentração de poderes na figura do presidente;

(vi) a criação do novo "regime extraordinário fiscal, financeiro e de contrataçôes" pela EC no 106/2020 tem caráter temporário (até o encerramento do estado de calamidade pública), e permite maior flexibilidade orçamentária ao desvincular o governo do cumprimento da regra de ouro constitucional;

(vii) a EC do Orçamento de Guerra simplifica a contratação de pessoal e de obras/ serviços/compras no âmbito do Executivo federal, continuando sujeita aos órgãos de controle, deixando para o Foverno Federal regulamentar os critérios para "distribuição de equipamentos e insumos de saúde", equivocamente, pois poderia ter traçado algumas diretrizes gerais;

(viii) a possibilidade de empresas com débitos previdenciários contratarem com a Administração Pública e/ou receberem benefícios e incentivos de ordem fiscal ou creditícia, conforme a EC no 106 ;

(ix) os juros e encargos da dívida serão pagos com os recursos provenientes das operaçôes de créditos realizadas para o refinanciamento da dívida mobiliária, representando um possível desvio na finalidade de combate à crise;

(x) a autorização dada ao Banco Central para comprar e vender títulos do Tesouro e outros ativos, e vendê-los nos mercados secundário local e internacional, desde que preenchidos dois requisitos: o ativo ter risco BB- ou superior e preço de referência publicado por entidade do mercado financeiro acreditada pelo Banco Central, com preferência aquisitória de títulos emitidos por microempresas e empresas de pequeno e médio porte; e 
(xi) a possibilidade de o Congresso Nacional sustar, por decreto legislativo, as decisôes do Executivo que descumprirem a emenda, sem prejuízo do controle das corregedorias e tribunais de contas. ${ }^{12}$

\section{Referências}

ALMAGRO-CASTRO, D. ¿Juicio legítimo o golpe de Estado encubierto? El impeachment a la Presidenta de la República Federal de Brasil, Dilma Rousseff. Rev. Derecho Estado, Bogotá, n. 42, p. 25-50, abr. 2019. Disponível em: <http://www.scielo.org.co/scielo.php?script=sci_ arttext\&pid=S0122-98932019000100025\&lng=en\&nrm=iso>. Acesso em: 31 jan. 2020.

ALMEIDA, R. Bolsonaro presidente, conservadorismo, evangelismo e a crise brasileira. Novos estud. CEBRAP. São Paulo, v. 38, n. 1, p. 185-213, Apr. 2019. Available from <http://www.scielo. br/scielo.php?script=sci_arttext\&pid=S0101-33002019000100010\&lng=en\&nrm=iso $>$. Access on: 2 mar. 2020. Epub May 06, 2019. https://doi.org/10.25091/s01013300201900010010.

ASSOCIAÇÃO BRASILEIRA DE NUTRIÇÃO. Criação da ADAPS: ataque ao SUS em meio à crise do coronavírus. Postado em 23/03/2020. Disponível em: <https://www.asbran.org. $\mathrm{br} /$ noticias/criacao-da-adaps-ataque-ao-sus-em-meio-a-crise-do-coronavirus $>$. Acesso em $27 \mathrm{de}$ março de 2020 .

BARIFOUSE, R. Coronavírus: por que o Brasil ainda não conseguiu fazer testes em massa? BBC News, São Paulo. 03 de abril de 2020.

BASTOS, P. P. Z. Ascensão e Crise do Governo Dilma Rousseff e o Golpe de 2016: Poder Estrutural, Contradição e Ideologia. Rev. econ. contemp., Rio de Janeiro, v. 21, n. 2, e172129, ago. 2017. Disponível em: <http://www.scielo.br/scielo.php?script=sci_arttext\&pid=S141598482017000200209\&lng=en\&nrm=iso>. Acesso em: 31 maio 2019.

BRASIL. Gabinete Civil. Emenda Constitucional no 106, de 8 de maio de 2020. Institui regime extraordinário fiscal, financeiro e de contrataçóes para enfrentamento de calamidade pública nacional decorrente de pandemia. Brasília, 2020a

BRASIL. Gabinete Civil. Lei no 13.979, de 6 de fevereiro de 2020. Dispóe sobre as medidas para enfrentamento da emergência de saúde pública de importância internacional decorrente do coronavírus responsável pelo surto de 2019. Brasília, 2020b. Disponível em: <http://www. planalto.gov.br/ccivil_03/_ato2019-2022/2020/lei/L13979.htm>

BRASIL. Gabinete Civil. Medida Provisória no 926, de 20 de março de 2020. Altera a Lei no 13.979, de 6 de fevereiro de 2020, para dispor sobre procedimentos para aquisição de bens, serviços e insumos destinados ao enfrentamento da emergência de saúde pública de importância internacional decorrente do coronavírus. Brasília, 2020c. 
BRASIL. Ministério da Saúde. Ministério da Saúde amplia para 46,2 milhôes aquisiçôes de testes. Publicado em 20 de abril de 2020 e atualizado em 22 de abril. Brasília, 2020d. Disponível em: https://www.saude.gov.br/noticias/agencia-saude/46760-ministerio-da-saude-amplia-para46-2-milhoes-aquisicao-de-testes. Acesso em: $1^{\circ}$ maio 2020.

BRASIL. Ministério da Saúde. Portaria No2.979, de 12 de novembro de 2019. Dispóe sobre o Programa Previne Brasil, que estabelece novo modelo de financiamento de custeio da Atenção Primária à Saúde no âmbito do Sistema Único de Saúde, por meio da alteração da Portaria de Consolidação no 6/GM/MS, de 28 de setembro de 2017. Brasília, 2019. Disponível em: http:// www.in.gov.br/en/web/dou/-/portaria-n-2.979-de-12-de-novembro-de-2019-227652180.

BRASIL. Senado Federal. Constituição Federal de 1988. Promulgada em 5 de outubro de 1988. Disponível em <http://www.planalto.gov.br/ccivil_03/constituicao/constituição.htm>. Acesso em: 26 mar. 2020.

CONSELHO NACIONAL DE SAÚDE. O SUS não pode morrer! Assine contra a redução de investimentos em saúde. Brasília, 2017. Disponível em: https://conselho.saude.gov.br/ultimas_ noticias/2017/08ago01_abaixoAssinadoEC95.html. Acesso em 10 de abril de 2020.

- Nota Pública: CNS reivindica revogação imediata de emenda que retirou verba do SUS, prejudicando enfrentamento ao coronavírus. Brasília, 2020. Disponível em: < http:// conselho.saude.gov.br/ultimas-noticias-cns/1064-nota-publica-cns-reivindica-revogacaoimediata-de-emenda-que-retirou-verba-do-sus-prejudicando-enfrentamento-ao-coronavirus $>$. Acesso em: 28 mar. 2020.

DAVID, G. Por que revogar a Emenda Constitucional 95, 18/12/2017. Outras Palavras. Disponível em: < https://www.inesc.org.br/por-que-revogar-a-emenda-constitucional-95/>. Acesso em: 28 mar. 2020.

DOMINGUES, J. M. Crise da república e possibilidades de futuro. Ciênc. saúde coletiva, Rio de Janeiro, v. 22, n. 6, p. 1747-1758, jun. 2017. Disponível em: <http://www.scielo.br/ scielo.php?script $=$ sci_arttext\&pid $=S 1413-81232017002601747 \& \operatorname{lng}=e n \& n r m=i s o>$. Acesso em: 29 maio 2019.

FIORI, J. L. História, estratégia e desenvolvimento: para uma geopolítica do capitalismo. São Paulo: Boitempo, 2014.

GIOVANELLA, L. et al. Médicos pelo Brasil: caminho para a privatização da atenção primária à saúde no Sistema Único de Saúde? Cad. Saúde Pública. Rio de Janeiro, v. 35, n. 10, e00178619, 2019. Disponível em: <http://www.scielo.br/scielo.php?script=sci_arttext\&pid=S0102-311X2 019001200303\&lng=en\&nrm=iso>. Epub Oct 28, 2019. https://doi.org/10.1590/0102311x00178619. Acesso em: 3 mar. 2020.

JOHNS HOPKINS UNIVERSITY. Coronavirus Resource Center. Available from: <https:// coronavirus.jhu.edu/map.html>. Acesso em: 2 abr. 2020. 
KLEIN, N. A doutrina do choque: a ascensão do capitalismo de desastre. Trad. Vania Cury. Rio de Janeiro: Nova Fronteira, 2008.

LAGO, I. O Jair que há em nós. Postagem em Blog autoral. Disponível em: https://www. cartamaior.com.br/?/Editoria/Sociedade-e-Cultura/O-Jair-que-ha-em-nos/52/47388. Acesso em: 28 fev. 2020.

MARIANO, C. M. Emenda constitucional 95/2016 e o teto dos gastos públicos: Brasil de volta ao estado de exceção econômico e ao capitalismo do desastre. Rev. Investig. Const., Curitiba, v. 4, n. 1, p. 259-281, abr. 2017. Disponível em: <http://www.scielo.br/scielo.php?script=sci_ arttext\&pid=S2359-56392017000100259\&lng=en\&nrm=iso $>$. Acesso em: 2 mar. 2020. Epub Apr 15, 2019. https://doi.org/10.5380/rinc.v4i1.50289.

MELLO, G. et al. A coronacrise: natureza, impactos e medidas de enfrentamento no Brasil e no mundo. Nota do Cecon. Campinas, n. 9, março de 2020. Disponível em: <https://www. eco.unicamp.br/images/arquivos/nota_cecon_oronacrise_natureza_impactos_e_medidas_de_ enfrentamento.pdf>. Acesso em: 27 mar. 2020.

MELO, E. A. et al. Mudanças na Política Nacional de Atenção Básica: entre retrocessos e desafios. Saúde em debate, Rio de Janeiro, v. 42, n. spe 1, p. 38-51, Sept. 2018. Available from $<$ http://www.scielo.br/scielo.php?script=sci_arttext\&pid=S0103-11042018000500038\&lng=en \&nrm=iso>. Acesso em: 3 mar. 2020. https://doi.org/10.1590/0103-11042018s103.

MENDES, A.; CARNUT, L.; GUERRA, L. D. S. Reflexóes acerca do financiamento federal da Atenção Básica no Sistema Único de Saúde. Saúde em debate, Rio de Janeiro, v. 42, n. spe 1, p. 224-243, Sept. 2018. Disponível em: <http://www.scielo.br/scielo.php?script=sci_ arttext\&pid=S0103-11042018000500224\&lng=en\&nrm=iso >. Acesso em: 3 mar. 2020. https://doi.org/10.1590/0103-11042018s115.

MORAIS, H. M. M. et al. Organizaçôes Sociais da Saúde: uma expressão fenomênica da privatização da saúde no Brasil. Cad. Saúde Pública, Rio de Janeiro, v. 34, n. 1, e00194916, 2018. Disponível em: <http://www.scielo.br/scielo.php?script=sci_arttext\&pid=S0102-311X2 018000105017\&lng=en\&nrm=iso >. Acesso em: 2 mar. 2020. Epub Feb 5, 2018. https://doi. org/10.1590/0102-.

NORONHA, J. C. et al. Notas sobre o futuro do SUS: breve exame de caminhos e descaminhos trilhados em um horizonte de incertezas e desalentos. Ciência \& Saúde Coletiva. Rio de Janeiro, v. 23, n. 6, p. 2051-2059, 2018.

OCKÉ-REIS, C. Entrevista: Carlos Ocké 'A Adaps pode reforçar a tendência de privatização da gestão’. Por Maíra Mathias - EPSJV/Fiocruz. Disponível em: < http://www.epsjv.fiocruz. br/noticias/entrevista/a-adaps-pode-reforcar-a-tendencia-de-privatizacao-da-gestao>. Acesso em: 1 mar. 2020. 
OLIVEIRA, G. M.; VERONESE, M. V. Brasil y el "fenómeno Bolsonaro": un análisis preliminar. Rev. mex. cienc. polit. Soc. México, v. 64, n. 237, p. 245-267, dic. 2019. Disponível em: $<$ http://www.scielo.org.mx/scielo.php?script=sci_arttext\&pid=S0185-19182019000300245\&ln g=es\&nrm=iso>. Acesso em: 27 mar. 2020. Epub 7 Nov 2019. http://dx.doi.org/10.22201/ fcpys.2448492xe.2019.237.68273.

OUTRA SAÚDE. Newsletter do Dia, por Redação. Disponível em: < https://outraspalavras. net/outrasaude/a-unimed-bate-a-porta-do-ministro/>. Acesso em: 27 mar. 2020.

PINTO, E. G.; XIMENES, S. B. Financiamento dos Direitos Sociais na Constituição de 1988: do "Pacto Assimétrico" ao "Estado de Sítio Fiscal". Educ. Soc. Campinas, v. 39, n. 145, p. 980-1003, dez. 2018. Disponível em: <http://www.scielo.br/scielo.php?script=sci_arttext\&pid=S010173302018000400980\&lng=en\&nrm=iso $>$. Acesso em: 2 mar. 2020. https://doi.org/10.1590/ es0101-73302018209544.

PISCITELLI, T. S. Comentários aos artigos 70 a 75 e 163 a 165. In: EQUIPE FORENSE. (Org.). Constituição Federal Comentada. Rio de Janeiro: Forense, 2018, v. 1, p. 700-719.

REBELLO, A. Profissionais da saúde compram EPI por conta própria para se proteger em SP. UOL, São Paulo, 6 abr. 2020.

ROZNAI, Y.; KREUZ, L R. C. Conventionality control and Amendment 95/2016: a Brazilian case of unconstitutional constitutional amendment. Rev. Investig. Const. Curitiba, v. 5, n. 2, p. $35-$ 56, ago. 2018. Disponível em: <http://www.scielo.br/scielo.php?script=sci_arttext\&pid=S235956392018000200035\&lng=en\&nrm=iso>. Acesso em: 2 mar 2020. https://doi.org/10.5380/ rinc.v5i2.57577.

SANTOS, I. S.; VIEIRA, F. S. Direito à saúde e austeridade fiscal: o caso brasileiro em perspectiva internacional. Ciênc. saúde coletiva, Rio de Janeiro, v. 23, n. 7, p. 2303-2314, jul. 2018. Disponível em: <http://www.scielo.br/scielo.php?script=sci_arttext\&pid=S1413-81232018000702303\&ln $\mathrm{g}=$ en\&nrm=iso $>$. Acesso em: 1 mar. 2020. https://doi.org/10.1590/1413-81232018237.09192018.

SANTOS, R. T. Bolsonaro, a pandemia e o compromisso com o mercado. Le Monde Diplomatique Brasil. Acervo Online | Brasil. 27 mar. 2020. Disponível em: <https://diplomatique.org.br/ bolsonaro-a-pandemia-e-o-compromisso-com-o-mercado/>. Acesso em: 27 mar. 2020.

SOUZA, L. E. P. F. et al. Os desafios atuais da luta pelo direito universal à saúde no Brasil. Ciênc. saúde coletiva, Rio de Janeiro, v. 24, n. 8, p. 2783-2792, ago. 2019. Disponível em: <http://www.scielo.br/scielo.php?script=sci_arttext\&pid=S1413-81232019000802783\&ln $\mathrm{g}=$ en\&nrm=iso $>$. Acesso em: 1 mar. 2020. Epub Aug 5, 2019. https://doi.org/10.1590/141381232018248.34462018 .

VIEIRA, D. Direito Financeiro. 2a ed. Salvador: Juspodivm, 2018a.

VIEIRA, F. S. Direito à saúde e austeridade fiscal: o caso brasileiro em perspectiva internacional. Ciência \& Saúde Coletiva, v. 23, p. 2303-2314, 2018b. 
VIEIRA, F. S.; BENEVIDES, R. P. Os impactos do Novo Regime Fiscal para o financiamento do Sistema Único de Saúde e para a efetivação do direito à saúde no Brasil. Brasília: Ipea, 2016. (Nota Técnica, n. 28). Disponível em: < http://repositorio.ipea.gov.br/bitstream/11058/7270/1/ NT_n28_Disoc.pdf>. Acesso em: 25 set. 2019.

VOLPE, R. A. et al. Repercussóes da Emenda Constitucional no 95/2016 no processo orçamentário. Brasília: Câmara dos Deputados; 2017. (Nota Técnica, n. 23).

\section{Notas}

${ }^{1}$ REDAÇÃO RBA (Rede Brasil Atual). Conselho Nacional de Saúde amplia campanha por revogação da EC 95, do teto de gastos. Por Redaçấo RBA. Publicado 17/03/2020 - 19h07. Disponível em: < https://www.redebrasilatual.com.br/saude-e-ciencia/2020/03/conselho-nacional-de-saude-revogacao-teto-gastos/>. Acesso em: 27 mar. 2020.

${ }^{2}$ SHALDERS, A. Em 3 pontos, o que pesquisa revela sobre relação entre eleitor e governo Bolsonaro. André Shalders da BBC News Brasil em Brasília. 25 set. 2019. Disponível em: < https://www.bbc.com/ portuguese/brasil-49834204>. Acesso em: 27 mar. 2020.

${ }^{3}$ Dados referentes à data de submissão deste artigo, 18 de maio de 2020.

${ }^{4}$ Também conhecido por "coronavoucher".

${ }^{5}$ Este caráter de morte se expressa cada dia mais, à medida que a pandemia se alastra pelo país.

${ }^{6}$ Ver mais em REBELLO, A. Profissionais da saúde compram EPI por conta própria para se proteger em SP. Do UOL, em São Paulo, 6 abr. 2020.

${ }^{7}$ Só no caso da UNIMED, que possui 18 milhóes de clientes, a ANS bloqueia R \$ 8 bilhóes para compor o ativo garantidor. Por razões mercadológicas, as empresas são contrárias a ele, como informado. No ano passado já estava em tramitação um Projeto de Lei para "modernizar" a Lei o 9656/1998 e excluir definitivamente o ativo garantidor.

${ }^{8}$ Várias entidades da saúde coletiva, como o CEBES, a ABRASCO e o SINMED-RJ assinaram uma nota contra a ADAPS, intitulada "Não à ADAPS, Sim a um SUS Forte" (ASBRAN, 2020).

${ }^{9}$ Operação de crédito, consoante o art. 29, III da LC no 101 (Lei de Responsabilidade Fiscal - LRF), é o "compromisso financeiro assumido em razão de mútuo, abertura de crédito, emissão e aceite de título, aquisiçấo financiada de bens, recebimento antecipado de valores provenientes da venda a termo de bens e serviços, arrendamento mercantil e outras operaçóes assemelhadas, inclusive com o uso de derivativos financeiros".

${ }^{10}$ Despesas de capital são gastos produtivos da Administração Pública voltados para a aquisição ou construçáo de bens de capital que contribuam para a formaçáo de novos bens. São, em resumo, gastos que geram crescimento patrimonial público (VIEIRA, 2018a).

${ }^{11}$ Ver mais em: DIZER O DIREITO. EC 106/2020: institui regime extraordinário fiscal, financeiro e de contrataçóes para enfrentamento da calamidade pública decorrente do coronavírus, 8 maio 2020.

${ }^{12}$ D. F. Cotrim Junior e L. M. S Cabral foram responsáveis pela concepção, planejamento estratégico, análise de dados, elaboração do texto, revisão e aprovação da versão final a ser publicada. 


\section{Abstract}

Federal Government actions in the fight

against coronacrisis: limits, insufficiencies and few successes

The article analyzes the actions of the Federal

Government in the context of combating Covid-19, establishing its limits, shortcomings and even the few successes, according to data available so far, given the fact that Constitutional Amendment (EC) No. $106 / 2020$ recently published, making it impossible to carry out a real analysis of its effects, which is why its institutes and possible reflexes were evaluated. Among the measures considered are: Law No. 13,979/2020, Provisional Measure (MP) No. 924/2020; Ordinance No. 395/2020; Ministry of Economy Plan of R \$ 147.3 billion; MP No. 296/2020; Decree No. 10,283/2020; and EC No. 106/2020. A deductive and inference approach methodology is used in the theoretical field, with historical and legal procedure methods. Finally, a series of conclusions are drawn, such as: the continuity of the link between the Federal Government and neoliberal rationality, which is part of its political platform, even when analyzing EC 106/2020; the need to revoke EC No. 95/2016, so that there is greater scope for action to contain damage; and the assessment that the greater part of the resources injected by the Federal Government in this fight do not constitute new credits, but rather the re-management and anticipation of future values already foreseen, differing from international state positions.

Keywords: Covid-19; neoliberalism; federative pact. 